\title{
SPIRITUALITAS THERESIA DARI KANAK-KANAK YESUS DAN WAJAH SUCI Studi atas Keterkaitan antara Pengenalan dan Penghayatan Spiritualitas Kongregasi Suster-Suster Abdi Kristus
}

\author{
Margareta Dwi Wahyuni
}

\begin{abstract}
:
The Congregation of the Sisters Servants of Christ (Abdi Kristus, AK) chose Saint Thérèse of the Child Jesus as their second patron. The purpose of this choice was that the AK sisters follow her life in their life of prayer, communion as well as mission. To determine whether the sisters have been familiar with the simplicity of life and spirituality of Saint Therèse, the author conducted this extensive research. The results lead to the conclusion that the introduction of the spirituality of Saint Thérèse of the Child Jesus still needs to be intensified with a study on her life, especially the life of prayer which is reflected in her autobiography and personal letters, particularly within the framework of the initial formation of the AK sisters.
\end{abstract}

\section{Kata-Kata Kunci:}

Spiritualitas, AK (Abdi Kristus), Theresia dari Kanak-kanak Yesus, Perutusan, Kesederhanaan.

\section{PENDAHULUAN}

Pada waktu itu, Keuskupan Agung Semarang masih menjadi bagian wilayah Vikariat Apostolik Batavia dengan Mgr. Petrus Johanes Willekens, SJ, sebagai pejabat Vikaris Apostolik Batavia. Beliau memiliki pandangan bahwa iman Kristiani perlu mengakar dalam budaya setempat sehingga Gereja khususnya di tanah Jawa memiliki wajahnya sendiri, seperti Gereja-gereja di negaranegara lain. Kondisi perang saat itu pun menumbuhkan kekhawatiran dalam diri beliau akan adanya kemungkinan penangkapan terhadap tenaga pastoral Gereja (romo, bruder, suster) yang berwarga negara asing. Hal ini semakin mendorong Mgr. P. J. Willekens, SJ untuk mendirikan seminari (tempat mendidik calon imam) dan kongregasi bruder, suster pribumi bagi penyiapan tenaga-tenaga pastoral Gereja pribumi.

Mgr. Willekens mendapat izin dari Sacra Congregatio de Propaganda Fide di Roma, untuk mendirikan kongregasi religius suster-suster pribumi. Lewat surat Kongregasi Suci Penyebar Iman, Prot. Num. 4711/37, berdasarkan Can. 492,
1, Kongregasi Suster Abdi Dalem Sang Kristus (ADSK) dinyatakan didirikan oleh Mgr. Willekens pada tanggal 29 Juni $1938 .{ }^{1}$ Hal yang unik dari kelahiran Kongregasi ADSK adalah bahwa kongregasi ini sudah disahkan berdiri sebelum ada anggotanya. Pada umumnya pendirian kongregasi diawali dengan berkumpulnya beberapa orang yang memiliki tujuan untuk melayani Gereja. Kemudian mereka meminta kepada pimpinan Gereja untuk mendirikan sebuah kongregasi. Setelah itu pimpinan Gereja mengeluarkan surat ijin pendirian kongregasi. Namun ini tidak terjadi pada saat pendirian ADSK.

Mgr. Willekens menamai kongregasi baru Abdi Dalem Sang Kristus dengan maksud seperti beliau tulis pada surat tertanggal 28 Februari 1938 kepada para pastor Vikariat Batavia yang berada di Jawa Tengah yang berbunyi:

...mengenai masalah yang akhir ini sangatlah ditentukan oleh nama yang akan kita berikan kepada suster-suster baru ini: Zusters dienaressen van Christus, Sustersuster Abdi Dalem Sang Kristus. Jiwa, yang 
ingin kita lihat akan menyemangati Kongregasi yang akan datang ini kiranya dapat kita gambarkan pada Para Wanita Suci di Injil, yang mengabdi kepada Kristus dengan kepenuhan hati yang tiada taranya dan di dalam ketekunan bekerja tanpa mengenal lelah. ${ }^{2}$

Jadi Kongregasi diberi nama Abdi Dalem Sang Kristus karena kongregasi diharapkan dapat menampilkan semangat pengabdian kepada Kristus melalui tugas-tugas mereka.

Kongregasi ADSK semakin berkembang dalam karya pelayanan. Para suster melayani tidak hanya di lingkungan orang Jawa. Mereka mulai berkarya dan bergaul dengan masyarakat luas di luar lingkungan orang Jawa. Sejak Bulan November 1967 komunitas biara suster ADSK tidak lagi menggunakan bahasa Jawa dalam berkomunikasi tetapi bahasa Indonesia. Nama Kongregasi Abdi Dalem Sang Kristus (ADSK) disebut juga Abdi Kristus (AK) berdasarkan keputusan rapat Dewan Pimpinan Umum, tanggal 15 Pebruari 1970 agar dapat dimengerti oleh orang-orang non Jawa. ${ }^{3}$

Tanda pengenal yang mudah dari para suster Abdi Kristus ialah salib jangkar yang bertuliskan "Ecce Ancilla Domini" (lihat aku abdi Tuhan). Dengan tanda ini, kongregasi ingin menyatakan diri sebagai abdi Kristus yang disalib dan dalam kesederhanaan iman menyerahkan diri kepada kuasa salib yang menyelamatkan. ${ }^{4}$

Pada Decretum (surat kekancingan/surat pendirian kongregasi) Kongregasi Abdi Kristus dituliskan oleh Mgr. Willekens sebagai berikut..."Maria, hamba dari Tuhan Allah, Kami pilih menjadi Pelindung dan pola hidup dari kongregasi ini." 5 Dengan pernyataan ini kongregasi ADSK memiliki pelindung Maria hamba Allah. Mgr. Willekens sebagai bapa pendiri telah memilihkan Maria hamba Allah sebagai pelindung bagi kongregasi. Pada surat beliau kepada para pastor Vikariat Batavia yang berada di Jawa Tengah, tertanggal 28 Februari 1938, beliau menuliskan juga “... supaya dengan perantaraannya para suster Dienaressen van Christus dapat ikut serta bekerja dengan penuh sukses supaya Kristus dapat meraja di hati orang di Jawa." Beliau berpengharapan para suster ADSK bekerja dengan perantaraan Maria. Namun Kongregasi Abdi Kristus setelah melewati beberapa waktu perjalanan mengabdiannya menambahkan St. Theresia dari Kanak-Kanak Yesus dan Wajah Suci sebagai pelindung kedua Kongregasi Abdi Kristus.

\section{THERESIA PELINDUNG KEDUA KONGREGASI AK}

Pencantuman Theresia dari Kanak-kanak Yesus sebagai pelindung kedua, di samping Maria hamba Allah yang merupakan pelindung pertama kongregasi, untuk pertama kali terdapat dalam, "Konstitusi Baru Suster-Suster ADSK" yang disahkan pada tanggal 17 Desember 1974 oleh Justinus Kardinal Darmojuwono sebagai uskup Keuskupan Agung Semarang. Dengan demikian mulai saat itu, Kongregasi Abdi Kristus mempunyai dua pelindung: Maria hamba Allah sebagai pelindung pertama dan Theresia dari Kanak-kanak Yesus sebagai pelindung kedua. Kongregasi memilih Theresia sebagai pelindung kedua pasti bukan untuk menggantikan peran Maria hamba Allah yang merupakan pelindung dan pola hidup Kongregasi Abdi Kristus.

Pada bab I Konstitusi Baru Suster-Suster ADSK itu dituliskan, "Santa Theresia dari KanakKanak Yesus, kita pilih jadi Pelindung kita yang kedua. Jalan rohaninya yang sederhana, kepercayaannya, penyerahan dirinya, menjadi jalan rohani kita juga”. Kongregasi melihat bahwa hidup Theresia yang sederhana, yang biasa merupakan sesuatu yang menarik. Dalam kesempatan wawancara dengan penulis, Sr. M. Xaveria sebagai suster perintis dan mantan pemimpin umum mengatakan:

\begin{abstract}
Karena kesederhanaan St. Theresia yang menarik suster-suster ADSK. Suster-suster ADSK memang rindu menjadi orang sederhana seperti Dewi Maria. Bunda Maria khan sederhana tetapi aduh, sulit sekali. Kalau St. Theresia itu orang biasa tetapi biasa dalam arti tampaknya, tetapi dia anak orang kaya, kekayaan itu tidak membuatnya rindu kenikmatan hidup tetapi kepada kesederhanaan, itu yang membuat St. Theresia menarik ${ }^{7}$.
\end{abstract}

Meskipun berasal dari keluarga berada (golongan masyarakat menengah ke atas), Theresia mau menghayati hidup dalam kesederhanaan. Theresia mampu hidup sederhana, baik dalam arti rohani maupun jasmani. Ia menyerahkan seluruh hidupnya pada Allah. Dan ia juga menghayati hidup sederhana sebagai seorang suster Karmel. Ia merasa bahagia dengan cara hidup sederhana seorang biarawati Karmel.

Lebih lanjut Sr. M. Xaveria mengatakan, ”St. Theresia kecil dipakai sebagai pelindung sustersuster AK sebenarnya karena cintanya kepada orang-orang miskin, khusus ADSK yang kecil, ADSK juga kecil jadi mirip seperti St. Theresia”, 
Kecil dan hidup tersembunyi itulah yang menarik. Hidup Theresia yang tersembunyi ini memberikan inspirasi dan peneguhan bagi Kongregasi AK dalam berkarya. Kongregasi AK sejak awal didirikan secara khusus diharapkan untuk bekerja di daerah pedesaan dan kota-kota kecil yang tidak terjangkau oleh kongregasi-kongregasi lain ${ }^{9}$. Karya-karya Kongregasi AK yang sederhana, tidak menonjol misalnya: mengelola TK di kotakota kecil, mengurus rumah tangga di rumah retret, rumah pendidikan calon imam, mengelola balai pengobatan di desa, bekerja sebagai guru SD, SMP dalam karya milik keuskupan. Lewat karya-karya kecil itu kongregasi mau berperan menyebarkan keselamatan Allah. Kongregasi mengidentifikasi diri sebagai kongregasi yang melakukan karya-karya kecil dan tersembunyi seperti Theresia yang kecil dan tersembunyi.

Pemimpin umum saat ini, Sr. M. Lisieux mengatakan," Maria memang pelindung pertama tetapi untuk dicontoh hidupnya kurang kongkrit dan cukup sulit. Dalam diri St. Theresia penghayatan sebagai hamba sangat jelas sehingga lebih mudah untuk diteladani ${ }^{10}$ ". Beliau memiliki keyakinan, Theresia merupakan contoh konkrit seorang yang mampu menghayati kesederhanaan iman Maria sebagai hamba Allah. Sikap kehambaannya dapat dilihat dengan jelas sehingga para suster akan lebih mudah meneladaninya.

Hidup Theresia sebagai seorang biarawati yang percaya dan menyerahkan diri kepada Tuhan, mengasihi semua orang, hidup sederhana, tekun melaksanakan tugas-tugas sederhana menampilkan sikap seorang hamba sehingga para suster AK akan lebih mudah meneladan sikap hamba Theresia dalam menghayati hidup panggilan dan perutusan mereka.

Theresia juga ingin "menyimpan segala sesuatu dalam hatinya" seperti Maria ${ }^{11}$. Dalam diam dan keheningan biara Karmel Theresia mendapatkan banyak kebahagiaan. Ia menjalankan tugas sehari-hari dengan diam. Segala derita yang dialami pun ia tanggung dalam diam agar para suster yang lain tidak tahu. Theresia selalu tersenyum sehingga mereka tidak melihat dan tidak tahu perjuangan, derita yang dialami Theresia. Dia diam tidak hanya mengenai kepentingannya sendiri tapi dia diam juga tentang kebijaksanaan terhadap orang lain. Theresia tidak pernah mengutarakan pendapatnya kalau tidak diminta oleh orang lain.

Theresia menjadi contoh konkrit pribadi yang mampu menghayati kesederhanaan Maria sebagai hamba Allah yang menjadi pola hidup Kongregasi
Abdi Kristus. Dengan demikian para suster akan lebih mudah meneladan sikap kesederhanaan sebagai hamba seperti yang telah dihidupi Theresia.

Theresia hidup tersembunyi dalam biara Karmel dan melaksanakan tugas pelayanan dalam pekerjaan-pekerjaan kecil, sederhana dengan cinta yang besar bagi Tuhan. Kongregasi dapat meneladan sikap Theresia ini. Kongregasi AK yang melakukan karya-karya kecil dan tersembunyi ini pun mau mengambil peran dalam mewartakan keselamatan Tuhan. Di bawah naungan Theresia Kongregasi AK mau melaksanaka karya itu melalui tugas-tugas kecil, sederhana dengan cinta yang besar kepada Tuhan.

\section{THERESIA DALAM KONSTITUSI KONGREGASI AK 1995}

Konstitusi menuliskan sebagian ungkapan pengalaman jiwa Theresia. Ungkapan-ungkapan ini menggambarkan perjalanan jiwa Theresia dalam pergulatan menuju ke kedalaman mistik sampai menemukan panggilannya. Theresia dalam menulis pengalaman hidupnya itu banyak menggunakan bahasa simbol. Bahasa yang menerangkan lebih dalam dari arti kata-kata itu sendiri. Ia mengungkapkan isi hatinya dengan memakai beberapa kata-kata simbol seperti anak kecil, menabur bunga, raja, duri-duri.

Konstitusi membahas Theresia mulai dari nomer 54 sampai dengan nomer 68 (15 nomor). Kelima belas nomor itu dapat dibagi sebagai berikut:

1) Pengantar, nomor 54.

2) Isi, nomor 55- 67 dan dapat dibagi dalam beberapa bagian:

a) Theresia mendapatkan rahmat Tuhan, nomor 55.

b) Keinginan dan kerinduan Theresia, nomor 56 - 59.

c) Theresia berproses untuk menemukan panggilannya, nomor 60- 62.

d) Cara-cara Theresia mewujudkan panggilannya, nomor 63- 67.

3) Penutup, nomor 68.

Kongregasi melihat bahwa Tuhan telah mengerjakan karya agung dalam diri Theresia. Kongregasi juga menyakini hanya cinta kepada Tuhanlah yang telah mengobarkan hati Theresia sehingga ia dimampukan untuk menyatukan diri dengan Tuhan dan membalas cinta-Nya. Melalui Konstitusi 1995, kongregasi menunjukkan Theresia sebagai: 
Pertama, Orang yang mempercayakan diri sepenuh hati kepada Allah. Theresia percaya bahwa Allah adalah Bapa yang maha baik dan ia adalah anak-Nya. Theresia menyakini bahwa segala yang diberikan Allah kepadanya merupakan anugerah. Maka Theresia selalu gembira menjalani hidup panggilan dan perutusannya meskipun ia mengalami kesulitan-kesulitan. Bahkan saat-saat ia menghadapi kesulitan menjadi kesempatan baginya untuk semakin memurnikan kepercayaannya kepada Tuhan. Ia merasakan baik dalam suka maupun duka, Tuhan selalu mengajar agar ia semakin dapat mencintai Tuhan dan sesama.

Kedua, Pribadi yang mempersembahkan diri sebagai kurban kepada cinta Allah yang berbelas kasih. Theresia merasakan, Allahlah yang mencintai dia lebih dahulu sehingga ia dipanggil secara khusus untuk hidup bagi-Nya. Ia sadar dirinya yang lemah, tak berdaya telah dipilih Allah menjadi kurban persembahan. Oleh karena itu, ia mau menggunakan segala yang dimiliki untuk melakukan kehendak Allah. Ia mau menyenangkan hati Allah dan mengembirakan sesama. Dan ia mempersembahkan segala kesulitan yang dialami sebagai kurban kasih.

Ketiga, Pejuang cinta yang tak mengenal kata menyerah dalam mengapai tujuan untuk mewujudkan cinta. Panggilan Theresia adalah Cinta dan Ia ingin menyebarkan cinta itu pada setiap orang. Theresia menginginkan orang semakin mencintai Yesus sebagaimana ia mencintai Yesus dan melakukan perbuatan-perbuatan yang menyenangkan hati-Nya. Bagi Theresia mencintai Allah berarti mencintai sesama. Dan ia membuktikan cinta itu dalam perbutan-perbuatan nyata. Theresia melandasi semua tindakannya dengan cinta yang murni bagi Allah. Hal ini menunjukkan bahwa ia sungguh-sungguh menjadi pewarta, pelaksana dan pejuang cinta.

\section{HIDUP DOA THERESIA}

Theresia adalah pribadi yang lahir, tumbuh dan berkembang dalam suatu lingkungan masyarakat. Ia memiliki dan mengalami berbagai ragam pengalaman berelasi dengan semua orang yang ditemuinya seperti: pengalamannya berelasi dengan anggota keluarga (bapak, ibu dan saudarisaudarinya, serta sanak saudaranya), pergaulannya dengan teman-teman dan guru-guru di sekolah serta di lingkungan Gereja. Theresia pun memiliki pengalaman berelasi dengan Tuhan lewat doadoanya. Ia sudah melaksanakan doa baik sebelum maupun setelah ia masuk biara Karmel. Hidup doa Theresia dapat diketahui dari buku otobiografinya.
Ia menuliskan kisah hidupnya (yang memuat juga hidup doanya) dalam gaya bahasa yang dapat mengajak pembacanya masuk dalam suasana doa. Ia menulis bukunya dengan corak kontemplatif. Ia seakan-akan mengajak para pembacanya untuk merasakan suasana doa biara Karmel yang hening.

Theresia memiliki ketekunan dalam hidup doa dan hidup saleh. Keluarga Theresia memberikan teladan sebagai orang katolik yang saleh. Mereka memberikan suasana yang memungkinkan untuk bertumbuh dan berkembangnya hidup doa Theresia. Kebiasaan-kebiasaan doa yang telah mereka lakukan bersama dalam keluarga memberikan kesan yang mendalam bagi Theresia sehingga ia selalu ingin melakukannya. Keluarga menjadi tempat pertama bagi Theresia dalam belajar berdoa.

Theresia merasakan kehidupan doanya dalam biara semakin berkembang dan mendalam. Theresia selalu berusaha mengikuti acara doa bersama dalam komunitas dan juga menjalankan doa pribadi. Dari pengalaman doa-doanya, Christopher O'Donnell dalam buku Prayer: Insights from St. Thérèse of Lisieux, membagi menjadi empat pengalaman doa Theresia yang penting dalam perjalanan hidupnya yaitu ${ }^{12}$ :

- Pada musim gugur 1894, di dalam doanya Theresia menemukan jalan kecil sebagai spiritual keanakan yang dihayatinya dalam hidup bersama para suster sekomunitas. Pengalaman doa ini semakin mengobarkan hatinya dalam mewujudkan cinta kasih kepada Tuhan melalui tindakan cinta kasih bagi sesama dan mempersembahkan segala perbuatan meskipun kecil untuk dipersembahkan kepada Tuhan dalam cinta.

- Pada tanggal 9 Juni 1895, Theresia mempersembahkan diri sebagai kurban bakaran kepada cinta Allah yang berbelas kasih. Dalam doanya Theresia merasakan sukacita, mengalami rahmat akan cinta Allah yang melimpah membanjiri jiwanya, membaharui jiwanya dan membersihkan dirinya dari dosa. Ia merasakan luapan cinta Tuhan sehingga ia digerakkan untuk membaktikan diri kepada Tuhan dengan pasrah, tanpa mengharapkan imbalan dalam melaksanakan kehendak-Nya. Itulah ungkapan kerinduan yang ada dalam hatinya untuk selalu menyenangkan hati Tuhan. Ia mau melakukan apa pun untuk menyenangkan hati Tuhan.

- Theresia mengalami pencobaan iman mulai paska 1896 sampai ia meninggal dan hal ini merupakan pengalaman kegelapan yang 
paling gelap. Dalam penderitaan fisik berat karena penyakit yang dideritanya, Theresia selalu berjuang untuk tetap mengimani bahwa Allah tetap mencintainya meskipun ia mengalami penderitaan. Theresia memiliki keyakinan penderitaan yang diterimanya dari Allah merupakan sesuatu yang terbaik bagi dirinya. Di balik awan gelap yang melandanya, Matahari cintanya tetap bersinar terang. Melalui doa-doanya, Theresia berusaha untuk tetap bersyukur, bersukacita walaupun ia berada pada kondisi sakit. Kelemahan fisik tidak mematahkan cintanya kepada Tuhan.

- Pada bulan Juli-Agustus 1896, ia semakin mengerti arti panggilannya menjadi kasih dalam hati Gereja. Ia menemukan panggilannya adalah cinta. Ketidakberdayaan fisik tidak menghalangi Theresia untuk mewujudkan cinta kepada Tuhan. Ia tetap mempersembahkan diri termasuk deritanya dalam doa pada Allah bagi Gereja (sesama suster sekomunitas, para misionaris, orang-orang berdosa agar bertobat, para imam). Ia mendaraskan doa-doa dengan semangat meskipun badannya tak berdaya. Ia ingin menjadi kasih dan bersemayam di dalam hati semua orang dalam hati Gereja serta menggerakkan semua orang untuk mencintai Tuhan.

Pengalaman-pengalaman doa itu menggambarkan perjuangan Theresia dalam mewujudkan cintanya kepada Tuhan dan doa-doanya bagi keselamatan Gereja.

Para rahib dan religius membaktikan hidup secara khusus bagi Tuhan dan salah satu bentuk kerasulan mereka adalah pelayanan doa. Maka setiap religius sebenarnya memiliki tugas pelayanan mendoakan orang lain. Pelayanan doa Theresia adalah doa yang ia lakukan untuk orang lain dengan pelbagai ujud dan kepentingan. ${ }^{13}$ Theresia banyak berdoa demi pertobatan orang berdosa dan keselamatan jiwa-jiwa serta untuk para imam. Ia juga mengajak orang lain untuk berdoa dan berkurban bersamanya bagi keselamatan jiwa-jiwa secara khusus para imam. ${ }^{14}$ Karena meskipun para imam mendapatkan anugerah luhur imamat tetapi mereka tetaplah manusia biasa. Mereka memiliki kelemahankelemahan sebagaimana manusia yang lain. Oleh karena itu, mereka perlu didoakan juga agar dapat menjalankan tugas sebagai imam dengan baik, sesuai martabat imamat yang luhur. Theresia secara khusus pula mendoakan dua saudara rohaninya, imam dan misionaris, yakni Adolphe Roulland dan Maurice Belliere ${ }^{15}$. Ia ingin merangkul dunia dalam doanya. Ia mau berdoa bagi semua orang di daerah misi yang akan mendapatkan keselamatan berkat pewartaan para misionaris.

Theresia menuliskan dalam otobiografinya, "Alangkah besar kekuatan doa. Kita dapat menyebutnya seorang ratu yang setiap saat dapat dengan leluasa menghadap seorang raja lalu memperoleh segala sesuatu yang dimintanya."16 Menurut Theresia segala permohonan melalui doa-doa akan dikabulkan oleh Bapa seperti yang telah diajarkan Yesus,” ... supaya apa yang kamu minta kepada Bapa dalam nama-Ku, diberikanNya kepadamu" (Yoh. 15:16). Tuhan mengabulkan doa-doa kita apabila kita minta dalam nama Yesus. Ia secara bebas mengungkapkan pada Tuhan dengan kata-kata yang sederhana. Theresia mengekspresikan perasaannya dengan kata-kata khas misalnya sebutan untuk Yesus: Kekasih ku, cintaku, hidupku dan sebutan untuk dirinya sendiri: kekasih-Mu, mempelai-Mu. Oleh karena itu, "Doa bagi Theresia adalah suatu luapan hati, sebuah pandangan yang sederhana ke surga. Suatu luapan syukur dan cinta, baik di tengah penderitaan maupun sukacita.”17 Sepanjang hidupnya, Theresia senantiasa berdoa sehingga doanya merupakan proses berkomunikasi dengan Allah terus menerus.

Doa Theresia mencerminkan hidupnya. Melalui doa-doa itu Theresia mengungkapkan semua isi hatinya sehingga dalam doa-doanya tergambarkan pribadi Theresia. Namun Theresia hanya menuliskan beberapa doanya saja. Doa-doa itu terkumpul sebanyak 21 doa yaitu:

1. "O Perawan Mariaku yang Terberkati”

2. [Surat Profesi]

3. Sebuah Tatapan Kasih Kepada Yesus

4. Penghormatan Kepada Tritunggal yang Mahakudus

5. "Bunga-Bunga Mistik"

6. Persembahan kepada Cinta Berbelaskasih

7. [Doa kepada Yesus di Tabernakel]

8. [Doa bagi Abbé Belliè]

9. Doa dari Céline dan Thérèse

10. [Persembahan Pagi]

11. "Buatlah Aku seperti-Mu Yesus"

12. Persembahan Kepada Wajah yang Kudus

13. "Putera Tunggal Bapa Abadi"

14. [Kepada Kanak-Kanak Yesus]

15. Karena pemberian-Mu bagiku Bapa Abadi

16. [Kepada Wajah Kudus]

17. "Tuhan Allah Balatentara"

18. "O Santo Sebastian yang Kudus"

19. [Persembahan Iman]

20. Doa Untuk Memperoleh Kerendahan Hati 


\section{1. "Seandainya Aku Ratu Surga"}

Doa-doa di atas merupakan bagian kecil dari banyaknya doa yang telah Theresia haturkan kepada Tuhan. Ia pasti sudah mendoakan lebih banyak doa-doa meskipun ia tidak menulis semuanya. Theresia menulis doa-doa yang disebut di atas itu setelah ia hidup sebagai Karmelites. Kumpulan doanya yang diawali dan diakhiri dengan doa kepada Maria menampakkan kedekatan Theresia dengan Maria. Theresia berusaha untuk menyatukan ungkapan hatinya dengan Maria dan ingin memberikan dirinya secara total bagi Allah dalam lindungan Maria. Theresia ingin seperti Maria dapat melaksanakan kehendak Tuhan sebagai seorang hamba.

Doa-doa Theresia menggambarkan berbagai macam keadaan. Guy Gaucher, O.C.D membagi doa-doa Theresia dalam tiga bagian ${ }^{18}$ :

a) Doa-doa spontan yang ia tulis pada saat ia menderita ataupun bahagia (Doa 1, doa 14-17, doa 19, doa 21).

b) Doa-doa yang bertujuan untuk mendidik bagi para novis (doa 3, 5, 7, 18, 20) dan satu doa untuk seseorang yang malas.

c) Doa-doa pada saat peristiwa-peristiwa yang penting dalam hidupnya (doa 2, 6, 8, 12)

Theresia membaca tulisan-tulisan Yohanes dari Salib yang merupakan salah satu tokoh Karmel. Dengan membaca buku "Malam Gelap Jiwa, Kidung Mazmur Rohani dan syair-syair yang lain, Theresia bagaikan mendapat ragi untuk segala sesuatu yang ditulis dan diucapkan. Ungkapan-ungkapan, tulisan-tulisan doa Theresia pun mendapatkan pengaruh dari karya-karya yang ia baca.

Theresia menuliskan beberapa kata pada doa 6 yang merupakan sebagian dari surat yang ditulis Yohanes dari Salib kepada Sr. Leonor dari Santo Gabriel, suster Karmelites Tak Berkasut di Cordoba. Ia mengutip kata-kata ini, "semakin banyak ingin Dia berikan, semakin hebat Dia membuat kita menginginkannya”. Theresia memasukkan kata-kata itu dalam doanya karena ia merasakan diperteguh. Seperti Sr. Leonor yang akan pindah dan membangun biara serta memiliki keinginan-keinginan di tempat baru demikian Theresia memiliki berbagai keinginan dan ia percaya keinginan itu akan dikabulkan Tuhan karena ia percaya pada sabda Yesus, "Semua yang kamu minta kepada Bapa atas nama-Ku, akan diberikan-Nya kepadamu”.
Pada doa 12 (Persembahan kepada Wajah Kudus) Theresia menuliskan sebagian dari katakata dalam Kidung Rohani 10 Yohanes dari Salib yaitu "semoga mataku boleh memandang-Mu". Yohanes dari salib menerangkan kata ini sama artinya dengan melihat dari muka ke muka. Theresia mengungkapkan kerinduannya untuk segera dapat melihat Allah. Theresia ingin bertemu dengan Tuhan secara langsung.

Theresia menuliskan kata "lira merdu" dalam doa 4 (Penghormatan kepada Tritunggal yang Mahakudus). Ia mengambil kata-kata itu dari Kidung Rohani 21"dalam musik lira merdu menyenangkan"19. Yohanes dari Salib menguraikan lira merdu berarti kemanisan yang dicurahkan Allah ke dalam jiwa dalam pertemuan rohani ini $^{20}$. Theresia mengharapkan jiwanya mendapatkan curahan kemanisan dari Allah.

Theresia menggunakan beberapa kata simbolis dari tulisan-tulisan Yohanes dari salib seperti kata: mempelai, kekasihku, bunga berkali-kali pada doa-doanya. Kata mempelai menunjuk diri Theresia sendiri yang mau menjadi mempelai wanita dalam perkawinan rohani. Theresia mengartikan kata kekasihku dengan Yesus. Bunga berarti cinta, kebajikan-kebajikan.

Meskipun Theresia mendapatkan pengaruh dari Yohanes dari Salib. Doa-doa Theresia tetap memiliki kekhasan. Theresia yang melalui jalan kecil dan tersembunyi tetap tampak dalam doadoanya.

\section{MENELITI SPIRITUALITAS DOA THERESIA DALAM KEHIDUPAN PARA SUSTER AK}

Kongregasi telah memilih Theresia sebagai pelindung kedua. Kongregasi pun memasukkan Theresia di dalam konstitusi kongregasi agar para suster dapat menghayati hidup panggilan dengan belajar kepada Theresia termasuk belajar dari kehidupan doanya. Sungguh sesuatu yang baik apabila para suster AK mengenal kehidupan Theresia untuk menjadikan teladan dalam hidup doa, berkomunitas maupun tugas perutusan. Untuk mengetahui apakah para suster telah mengenal dengan baik Theresia dan menjadikan teladan dalam menghayati panggilan dalam kesederhanaan hidup dan karya maka penulis mengadakan penelitian pada bulan September sampai bulan November 2013.

Langkah-langkah penelitian tersebut meliputi: penentuan variabel penelitian, paradigma pene- 
litian, sampel sumber data, teknik pengumpulan data dan analisis data.

\subsection{Variabel Penelitian ${ }^{21}$}

Variabel penelitian adalah suatu atribut atau variasi atau nilai dari orang, obyek atau kegiatan yang mempunyai variasi tertentu yang ditetapkan oleh peneliti untuk dipelajari dan kemudian ditarik kesimpulannya. Variabel dalam penelitian ini adalah:

\subsubsection{Pengenalan Suster AK Terhadap Theresia}

Pengenalan Theresia merupakan variabel bebas. Variabel bebas merupakan variabel yang mempengaruhi atau yang menjadi sebab perubahannya. Pengenalan Theresia yang dimaksudkan di sini adalah para suster mengetahui riwayat hidupnya seperti saat-saat penting dalam hidup Theresia yang mempengaruhi hidup panggilannya, hidup dan semangat doanya, hidup berkomunitasnya.

\subsubsection{Hidup Doa yang Benar}

Penghayatan hidup doa adalah variabel terikat. Variabel terikat merupakan variabel yang dipengaruhi karena adanya variabel bebas. Penghayatan hidup doa yang benar adalah bagaimana para suster telah menjalankan hidup doa baik secara pribadi maupun bersama-sama dalam komunitas. Hubungan pengenalan Theresia akan mempengaruhi penghayatan hidup doa. Para suster yang mengenal Theresia dengan baik akan melaksanakan hidup doa dengan lebih baik dan mampu membatinkan keutamaan Theresia sehingga menjadi milik pribadi.

\subsubsection{Perwujudan Hidup Doa dan Buah-Buah Rohani}

Perwujudan hidup doa dan buah-buah rohani merupakan variabel terikat. Variabel terikat merupakan variabel yang dipengaruhi karena adanya variabel bebas. Perwujudan hidup doa dan buah-buah rohani adalah bagaimana para suster mempraktekan buah-buah doanya. Apa yang ditemukan dalam doa diwujudkan para suster dalam hidup berkomunitas dan tugas perutusan. Bagaimana para suster telah meneladan kehidupan Theresia.

\subsection{Paradigma Penelitian}

Paradigma penelitian yang dimaksud adalah pola pikir yang menunjukkan kaitan antara variabel yang akan diteliti. Kaitan ketiga variabel tersebut dalam penelitian ini dapat digambarkan sebagai berikut:

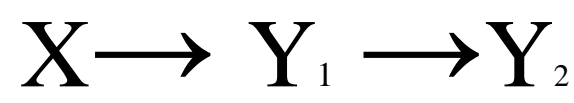

$\mathrm{X}$ : Pengenalan Theresia

Y1: Hidup doa yang benar

Y2: Perwujudan hidup doa dan buah-buah rohani

Grafik di atas menjelaskan: Bagaimana pengenalan terhadap Theresia sebagai variabel bebas $(\mathrm{X})$ berkaitan dengan hidup doa yang benar (Y1), perwujudan hidup doa dan buah-buah rohani (Y2) sebagai variabel terikat. Pengenalan terhadap Theresia akan mempengaruhi hidup doa para suster. Mereka akan menjalankan doa dengan benar. Doa sebagai tempat bertemu dengan Tuhan sehingga mereka mampu membatinkan nilai-nilai Kerajaan Allah (dalam tulisan ini keutamaan Theresia) dan nilai-nilai Kerajaan Allah itu menjadi milik pribadi serta siap untuk diwujudkan sebagai buah-buah rohani. Doa mempunyai pengaruh baik dalam kehidupan kalau doa mempertemukan pendoa dengan Tuhan.

\subsection{Sampel Sumber Data}

Sampel adalah bagian dari jumlah dan karakteristik yang dimiliki oleh sebuah populasi. Penulis memilih beberapa suster yang akan menjadi sampel sumber data atau informan dalam penelitian ini. Apa yang dipelajari dari sampel itu dan kesimpulannya akan diberlakukan untuk populasi/kongregasi. Dengan demikian, sampel yang diambil dari populasi harus dapat mewakili populasi (representatif). Teknik pengambilan sampel dalam penelitian ini adalah simple random sampling karena pengambilan anggota sampel dari populasi dilakukan secara acak tanpa memperhatikan strata yang ada dalam populasi $i^{22}{ }^{22}$. Semua suster dapat menjadi sampel. Sampel yang dipilih akan menjadi sampel sumber data dalam penelitian.

Para suster ini (baik yang kaul kekal ataupun kaul sementara) telah menghayati hidup dalam komunitas dan tugas perutusan. Mereka diharapkan dapat memberikan informasi kepada penulis mengenai pengaruh mengenalan St. Theresia dari Kanak-Kanak Yesus dalam penghayatan hidup doa dan hidup bersama serta tugas perutusan. Penulis mengambil sampel sumber data sejumlah 60 suster dari jumlah keseluruhan suster AK. Dalam katalog sustersuster AK Per Januari 2013, tercatat jumlah suster 
AK adalah 151 suster $^{23}$ sehingga jumlah 60 suster sebagai sampel merupakan $40 \%$ dari populasi anggota Kongregasi AK.

\subsection{Teknik Pengumpulan Data}

Penulis melakukan beberapa langkah untuk pengumpulan data-data penelitian. Langkah pertama adalah menentukan metode yang akan digunakan untuk mengumpulkan data. Penulis menggunakan angket. Angket merupakan teknik pengumpulan data yang dilakukan dengan cara memberikan seperangkat pertanyaan atau pernyataan tertulis kepada responden untuk dijawabnya ${ }^{24}$.

Langkah berikutnya adalah wawancara. Penulis dalam langkah ini mengadakan wawancara pendalaman dengan beberapa sampel sumber data terpilih. Tujuan dari wawancara ini adalah untuk melihat hal-hal dari data hasil angket yang barangkali belum jelas dan perlu diperjelas.

Penulis membuat angket sebagai alat mengumpulkan data dengan menggunakan skala pengukuran tipe pilihan dan jawaban. Para suster memilih satu jawaban yang tersedia dan menjawab pertanyaan pada pertanyaan-pertanyaan terbuka.

\subsection{Teknik Analisis Data}

Analisis data merupakan langkah berikutnya setelah data dari semua sumber data terkumpul. Kegiatan-kegiatan dalam analisis data meliputi: mengelompokkan data berdasarkan variabel dan jenis responden, mentabulasi data berdasarkan variabel dari seluruh responden, menyajikan data setiap variabel yang diteliti, melakukan perhitungan untuk menjawab rumusan masalah dan melakukan perhitungan untuk menguji hipotesis yang telah diajukan dan mendeskripsikan hasil perhitungan itu ${ }^{25}$.

Penulis melakukan penelitian dengan metode kuantitatif sehingga akan memperoleh data penelitian berupa angka-angka. Karena data-data penelitian berupa angka-angka maka penulis memakai analisis statistik ${ }^{26}$.

Dalam penelitian kuantitatif ada dua macam statistik yang digunakan untuk menganalisis yaitu statistik deskriptif dan statistik inferensial ${ }^{27}$. Penulis akan menggunakan statistik deskriptif untuk menganalisis data-data yang telah ada. Statistik deskriptif adalah statistik yang digunakan untuk menganalisis data dengan cara mendeskripsikan atau menggambarkan data yang telah terkumpul sebagaimana adanya tanpa bermaksud membuat kesimpulan yang berlaku untuk umum ${ }^{28}$. Termasuk dalam statistik deskriptif antara lain adalah penyajian data melalui tabel, perhitungan persentase, grafik, diagram lingkaran. Dalam statistik deskriptif juga dapat dilakukan mencari kuatnya hubungan antara variabel melalui analisis korelasi, membuat perbandingan dengan membandingkan rata-rata data sampel.

\subsection{Hasil Penelitian}

Setelah penulis mengolah data-data dari responden. Beberapa hal dapat disimpulkan sebagai berikut:

Pertama, semua responden mengetahui Theresia sebagai pelindung kedua, tetapi belum semua memiliki pengetahuan tentang Theresia sebagai pelindung kedua kongregasi. Beberapa suster tidak memiliki pengetahuan dalam arti mereka tidak tahu alasan-alasan kongregasi menambahkan Theresia sebagai pelindung ke kedua. Hal ini terjadi karena belum semua suster mendapatkan pendalaman mengenai Theresia sebagai pelindung kedua secara khusus para suster yang sudah kaul kekal. Sebaliknya para suster yang belum kaul kekal sudah mendapatkan pendalaman mengenai Theresia sebagai pelindung kedua . Beberapa suster membuat pendalaman secara pribadi dengan membaca otobiografi Theresia atau bersama komunitas membahas otobiografi tersebut. Para suster yang belum kaul kekal meskipun sudah mendapat pendalaman mengenai Theresia tetapi ada beberapa yang belum pernah membaca otobiografi Theresia. Semua hal di atas menyebabkan mutu pengenalan sebagian para responden tentang Theresia sebagai pelindung kedua belum menyeluruh.

Kedua, sebagian responden melaksanakan doa pribadi dengan lama waktu berdoa berbeda-beda antara 10'-60'. Beberapa responden menjalankan meditasi secara rutin. Mereka mengatasi kesulitankesulitan dalam berdoa dengan beberapa cara seperti menciptakan keheningan hati, membaca kembali bahan doa. Dalam hidup doa komunitas, belum semua komunitas responden dapat selalu melaksanakan. Komunitas-komunitas yang ada anggota yang belum kaul kekal masih dapat melaksanakan doa komunitas secara teratur. Namun ada komunitas yang tidak melakukan doa komunitas. Responden juga belum mengenal dan mendoakan doa-doa Theresia. Hal-hal tersebut di atas membuat mutu hidup doa sebagian responden tidak mendalam.

Ketiga, para responden mau meneladan hidup Theresia dalam berkomunitas. Responden ingin 
meneladan sikap Theresia yang tekun berdoa, sikap ramah terhadap semua orang. Sebagian besar responden menghadapi orang yang bersalah dengan cara mendoakan mereka. Kehidupan responden menghayati kesederhanan dalam hidup. Mereka merelakan orang lain mengambil barang penting mereka karena melihat orang lain lebih membutuhkan. Mereka menggunakan HP sebagai sarana untuk memperlancar tugas. Meskipun sebagian kecil responden masih kurang bijaksana dalam menggunakan HP (sebagian responden yang sudah kaul kekal). Mereka memakai sebagian besar SMS dan telpon untuk keperluan keluarga, sahabat dan kenalan. Sebagian responden memiliki sikap siap sedia untuk menggantikan tugas rekan sekomunitas. Para responden masih perlu berjuang bersama-sama untuk menciptakan komunitas yang baik. Mereka masih perlu untuk mengembangkan sikap saling mendukung.

Keempat, ada beberapa fakta menarik yang berkaitan dengan responden Yang sudah kaul kekal. Sebagian dari mereka belum pernah mendapatkan pemahaman mengenai Theresia sebagai pelindung kedua. Sebagian dari mereka juga tidak melaksanakan doa komunitas secara teratur. Beberapa diantara mereka kurang bijaksana dalam menggunakan hp karena sebagian besar SMS dan tilpon digunakan untuk keperluan kontak dengan para kenalan. Secara keseluruhan responden belum mengenal dan mendoakan doadoa Theresia.

Kelima, hipotesa ada keterkaitan antara pengenalan terhadap Theresia, hidup doa yang benar, perwujudan hidup doa dan buah-buah rohani dalam hidup bersama terbukti. Hasil penelitian menampilkan bahwa responden yang belum kaul kekal pernah membaca otobiografi Theresia dan mereka selalu melakukan doa bersama serta mereka juga menggunakan sebagian besar SMS dan telpon untuk keperluan karya dan kongregasi. Sebaliknya ada responden yang belum pernah membaca otobiografi Theresia dan sebagian dari mereka melaksanakan doa komunitas dengan frekwensi kadang-kadang bahkan ada responden yang tidak pernah doa bersama dalam komunitas.

Kenyataan-kenyataan di atas tentu memberikan pengaruh kepada para suster dalam menghayati panggilan. Para responden yang belum mengenal hidup Theresia dengan baik tentu akan mengalami kesulitan untuk meneladannya. Mereka kurang membatinkan keutamaan-keutamaan Theresia sehingga mereka pun tidak dapat mewujudkan hidup doa dan buah-buah rohani dalam hidup bersama.

Persoalan-persoalan tersebut perlu mendapatkan pemecahannya. Langkah-langkah pastoral perlu dibuat agar para suster semakin mampu untuk meneladan Theresia.

\section{PENUTUP: SARAN LANGKAH PASTORAL}

Kongregasi AK telah memilih Theresia sebagai pelindung kedua, teladan dalam menghayati panggilan dalam kesederhanaan dan kesahajaan hidup dan karya (Konst. 54). Kongregasi pun menuliskan dalam konstitusi hal-hal yang diajarkan Theresia bagi kongregasi sehingga semua anggota dapat meneladan hal-hal yang sama dari Theresia sebagai satu kesatuan kongregasi.

Konstitusi sebagai pegangan para suster dalam menghayati hidup sebagai seorang AK telah memberikan beberapa pedoman dalam hidup doa. Konstitusi mengajak para suster untuk selalu memperbarui hidup doa pribadi maupun hidup doa bersama dalam komunitas secara terus menerus (Konst. No. 262, 259). Konstitusi juga mengingatkan para suster untuk mendoakan orang lain (Konst. 254). Konstitusi telah menuangkan semangat doa Theresia sehingga para suster akan sangat terbantu dalam melaksanakan keteladanan Theresia.

Penulis melihat bahwa kongregasi dapat dan perlu menindaklanjuti hasil penelitian agar para suster semakin mengenal Theresia sehingga semakin mampu pula untuk meneladan dalam hidup sehari-hari. Di bawah ini penulis memberikan beberapa saran langkah pastoral berdasarkan hasil penelitian bagi kongregasi untuk semakin memperkenalkan Theresia dan upaya menumbuhkan doa Theresia:

Pertama, kongregasi penting menetapkan otobiografi Theresia sebagai buku bacaan wajib bagi suster AK sehingga para suster mengetahui kehidupan Theresia. Secara khusus di novisiat para novis mendalami otobiografi ini. Mereka tidak hanya membaca tetapi mereka juga menuliskan hal-hal menarik dari Theresia serta mengungkapkan kecintaan terhadap Theresia dengan menulis mengenai Theresia. Kongregasi hendaknya mengadakan pendalaman mengenai kehidupan Theresia dalam kelompok-kelompok (Yunior, medior, senior) dengan materi-materi khusus secara berkesinambungan. 
Kedua, kongregasi perlu menuliskan sejarah dan alasan-alasan Theresia sebagai pelindung kedua. Kongregasi dapat menugaskan seorang suster ataupun membentuk satu tim untuk tugas tersebut di atas. Kemudian kongregasi membukukannya secara sistematis dan menyebarkannya kepada seluruh anggota sehingga semua suster memiliki pemahaman yang sama mengenai Theresia sebagai pelindung kedua.

Ketiga, kongregasi perlu memperkenalkan doa-doa yang ditulis oleh Theresia. Kongregasi hendaknya menugaskan seorang/beberapa orang suster/tim khusus untuk menerjemahkan semua doa-doa yang ditulis oleh Theresia. Kemudian kongregasi menyusun doa-doa itu menjadi sebuah buku sehingga para suster dapat membacanya dan mendoakannya secara pribadi sesuai dengan kebutuhan mereka.

Keempat, Kongregasi perlu menggunakan beberapa doa Theresia sebagai salah satu doa kongregasi sehingga para suster mendoakan bersama-sama doa-doa yang didoakan Theresia, sehingga kongregasi, para suster akan dapat memperoleh rahmat seperti Theresia. Kongregasi sebaiknya memasukkan doa 7 (Doa kepada Yesus di Tabernakel) dan doa 20 (Doa untuk Memperoleh Kerendahan Hati) dimasukkan dalam buku doa kongregasi sebagai doa-doa khas suster AK.

Penulis mengusulkan doa 7 (Doa kepada Yesus di Tabernakel) dan doa 20 (Doa untuk Memperoleh Kerendahan Hati) dengan pertimbangan: doa-doa ini merupakan doa-doa yang digunakan Theresia untuk mendidik agar seseorang selalu melakukan refleksi dan memiliki kerendahan hati. Penulis melihat bahwa seorang suster abdi Kristus perlu memiliki sikap reflektif dan rendah hati dalam hidup sehari-hari. Dengan mendoakan doa tersebut, para suster secara tidak langsung mendapatkan didikan dari Theresia. Para suster AK dapat memohon sikap-sikap tersebut melalui doa-doa yang rutin dan benar. Mereka perlu mengupayakan doa menjadi tempat bertemu dengan Tuhan, membatinkan nilai-nilai yang benar di hadapan Tuhan.

Hasil penelitian menunjukkan bahwa pengenalan terhadap Theresia, hidup doa yang benar memegang peran penting dalam hidup para suster AK). Oleh karena itu, para suster AK perlu untuk senantiasa menjaga hidup doanya. Mereka tinggal, bergaul dan berkarya di tengah-tengah masyarakat sehingga mereka kemungkinan mendapat pengaruh buruk dari masyarakatnya, dunia modern. Di tengah-tengah masyarakat seperti itu seseorang mendapat tantangan untuk tetap menjaga hidup doanya. Ada faktor-faktor yang dapat menyebabkan hidup doa seseorang menurun seperti masalah pribadi, kesulitan mengatur waktu karena kesibukan pekerjaan, kondisi zaman modern yang menuntut serba cepat. Namun faktor-faktor itu masih memerlukan penelitian lain. Hasil penelitian ini dapat menjadi satu pintu untuk memulai penelitian lain yang berkaitan dengan hidup doa.

\section{Margareta Dwi Wahyuni}

Pengajar di Sekolah Dasar St. Antonius Cakra

Negara di Mataram Lombok.

Email:m_dwi_ak@yahoo.co.id

\section{CATATAN AKHIR}

${ }^{1}$ Konstitusi Tarekat Abdi Kristus, Decretum (surat kekancingan), 6.

2 Setyakarjana, Selintas Sejarah Kongregasi Biarawati Abdi Kristus, Yogyakarta 2003, 18.

3 Setyakarjana, 90.

${ }^{4}$ Tarekat Abdi Kristus, Konstitusi Tarekat Abdi Kristus, No. 37.

${ }^{5}$ Konstitusi Tarekat Abdi Kristus, DECRETUM, 6.

${ }^{6}$ Setyakarjana, 19.

7 Wawancara dengan Sr. M. Xaveria, AK, Ungaran 11 Januari 2013.

${ }^{8}$ Wwawancara dengan Sr. M. Xaveria, AK.

${ }^{9}$ Konstitusi Baru Suster-Suster ADSK, Decretum (surat kekancingan), 8.

${ }^{10}$ Wawancara dengan Sr. M. Lisieux, AK, Ungaran 16 Maret 2013.

${ }^{11}$ Friederike Gorres Ida, Wajah Tersembunyi, Kehidupan Teresia Lisieux, Kanisius, Yogyakarta 1985, 443-444.

${ }^{12}$ Christopher O'Donnell, Prayer: Insights from St. Thérèse of Lisieux, 25-26.

${ }^{13}$ Buyung Florianus, O.Carm, Daya tarik Cinta Ilahi, Karmelindo, Malang 2009, 96.

${ }^{14}$ Theresia, Collected Letters of St. Therese of Lisieux,Transl. FJ Sheed, Sheed \& Ward, London 1972, 98.

${ }^{15}$ Buyung Florianus, O.Carm, Daya tarik Cinta Ilahi, 97.

${ }^{16}$ Theresia, Aku Percaya Akan Cinta Kasih Allah, 201.

${ }^{17}$ Theresia, Aku Percaya Akan Cinta Kasih Allah, 201.

${ }^{18}$ St. Thérèse, The Prayers of St. Thérèse of Lisieux, Transl. Aletheia Kane, O.C.D, 16.

${ }^{19}$ Kavanaugh K, O.C.D \& Rodriguez O, O.C.D, Karya Kecil Yohanes dari Salib, 118.

${ }^{20}$ Kavanaugh K, O.C.D \& Rodriguez O, O.C.D, Karya Kecil Yohanes dari Salib, 194.

${ }^{21}$ Sugiyono, Metode Penelitian Pendidikan, Pendekatan Kuantitatif, Kualitatif, dan $R \& D$, Alfabeta, Bandung 2013, 60-62.

${ }^{22}$ Sugiyono, Metode Penelitian Pendidikan, Pendekatan Kuantitatif, 120.

${ }^{23}$ Kongregasi Biarawati Abdi Kristus, Katalog SusterSuster AK Per Januari 2013, 21. 
${ }^{24}$ Sugiyono, Metode Penelitian Pendidikan, Pendekatan Kuantitatif, 199.

${ }^{25}$ Sugiyono, Metode Penelitian Pendidikan, Pendekatan Kuantitatif, 207.

${ }^{26}$ Sugiyono, Metode Penelitian Pendidikan, Pendekatan Kuantitatif ,13.

${ }^{27}$ Sugiyono, Metode Penelitian Pendidikan, Pendekatan Kuantitatif ,207.

${ }^{28}$ Sugiyono, Metode Penelitian Pendidikan, Pendekatan Kuantitatif, 207-208.

\section{DAFTAR RUJUKAN}

\section{Sumber Primer}

1985, Aku Percaya Akan Kasih Allah, diterjemahkan oleh biarawati Karmel Bajawa, Ende, Nusa Indah. ,1997, The Prayers of Saint Thérèse of Lisieux, Translated by Aletheia Kane, O.C. D, ICS of Carmelite Studies, Washington, DC.

St. Therese of Lisieux,1976, Story of A Soul The Autobiography of Saint Thèrése of Lisieux, Translated From the Original Manuscripts by John Clarke, O.C.D, ICS Publications, Washington, DC.

\section{Sumber Sekunder}

2010, Mudah Belajar Statistik dengan SPSS 18, (Editor Agustina S), Wahana Komputer dan C.V. Andi Offset, Yogyakarta.

, (Pengantar),1985, Menuju Hidup Baru, Pesan Terakhir Teresia Lisieux, Kanisius, Yogyakarta.

2003,Carmelite Prayer, A Tradition for the $21^{\text {st }}$ Century, Egan Keith, J (editor), Billy Dennis, CSsR,2009, Suara hati \& Doa, Belajar Terbuka Pada kebenaran, Kanisius, Yogyakarta.

,1990, By Love Alone, Daily Readings With St. Thérèse of Lisieux, Hollings Michael (editor), Darton, Longman and Todd, London.

,2001 Prayer: Insights from St. Thérèse of Lisieux, Veritas Publications, Ireland.

,1995, Konstitusi Tarekat Abdi Kritus, Semarang.

Buyung Florianus, O.Carm,2009, Daya Tarik Cinta Ilahi, Kisah Hidup dan Panggilan St. Theresia dari Lisieux, Karmelindo, Malang.
Darminta, SJ, 1981, Doa Berdoa, Kanisius, Yogyakarta.

De Messter Koen, Karmelit, 1984, Tangan Kosong, Teresia dari Lisieux, Kanisius, Yogyakarta.

Paulist Press, New Jersey.

Gaucher Guy, O.C.D,1997, The Prayer of Saint Therese of Lisieux, Transl, Aletheia Kane, O.C.D, Institute of Carmelite Studies, Washington, DC.

Heuken, A, 2005, Ensiklopedia Gereja Jilid V, Ko-M, Yayasan Cipta loka Caraka, Jakarta.

Ida Friederike Gorres,1985, Wajah Tersembunyi, Kehidupan Teresia Lisieux, Kanisius, Yogyakarta

Jacobs Tom, SJ, 2004, Teologi Doa,Kanisius, Yogyakarta.

Kavanaugh Kieran, O.C.D \& Rodriguez Otilio, O.C.D,1991 Karya Kecil Yohanes dari Salib, Dioma, malang.

Kongregasi Biarawati Abdi Kristus, 2013, Katalog suster-Suster AK PerJanuari

Liagre Pere, c. s. sp, 1997, Berpadang Gurun Bersama St. Theresia dari Kanak-Kanak Yesus, diterjemahkan oleh Sr. Marie Thèrèse, Biara Karmel, Lembang.

Muskens,1970, Sejarah Gereja Katolik Indonesia Jilid 3b, Arnoldus, Ende Flores.

Nouwen Henri,1973, Tangan Terbuka. Catatan tentang doa, Kanisius, Yogyakarta.

O’Donnell Christopher, OCarm,1997, Love in the heart of the Church, The Mission of Térèse of Lisieux, Veretas, Dublin

Pennock, Michael Francis,1987, The Ways of Prayer, An Introduction, Ave Maria Press, Notre Dame, Indiana.

Setyakarjana,2003, Selintas Sejarah Kongregasi Biarawati Abdi Kristus, Yogyakarta.

Tarekat Abdi Kristus,1974, Konstitusi Baru Suster-Suster ADSK, Ungaran semarang.

Tim KAS,1992, Garis-Garis Besar Sejarah Gereja Katolik Keuskupan Agung Semarang, Keuskupan Agung Semarang, Semarang.

Tim Pembinaan Kongregasi AK,2003, Pedoman Pembinaan Kongregasi AK (Draf), AK, Ungaran Semarang.

Yohanes Paulus II,2009 ,Kompendium Katekismus Gereja Katolik, diterjemahkan oleh Harry Susanto, SJ, Kanisius, Yogyakarta. 